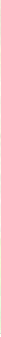

\title{
UM ESTUDO DA CONSCIÊNCIA AMBIENTAL NA GESTÃO DOS RESÍDUOS SÓLIDOS NO INTERIOR DO ESTADO DE SÃO PAULO E NA REGIÃO DO TRIÂNGULO MINEIRO
}

A study of environmental awareness in solid waste management in the interior of the State of São Paulo and Triângulo Mineiro Region

Un estudio de la conciencia ambiental en la gestión de los residuos sólidos en el interior del Estado de São Paulo y en la Región del Triángulo Minero

\author{
Larissa Marçon \\ Graduanda, FEA-RP/USP, Brasil \\ larissa_mr@hotmail.com
}

Sonia Valle Walter Borges de Oliveira Professora Associada, FEA-RP/USP, Brasil soniavw@terra.com.br

Marcelo Elias dos Santos

Doutorando, FEA-RP/USP, Brasil santosmarceloelias@gmail.com 


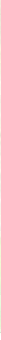

RESUMO

Esta pesquisa pretende identificar quais ações são necessárias para ampliar a conscientização ambiental e a participação da população na gestão ambientalmente adequada dos resíduos sólidos. Para isso, foi avaliada a problemática da gestão dos resíduos sólidos sob a ótica da conscientização ambiental e do engajamento da sociedade. $\mathrm{O}$ estudo realizado utilizou a pesquisa exploratória com enfoque quantitativo. Os dados foram coletados por meio de um questionário aplicado em municípios presentes no interior do estado de São Paulo e na região do Triângulo Mineiro, e foram analisados por meio da estatística descritiva. O resultado final deste trabalho foi o desenvolvimento de um panorama geral que mostrou a percepção da amostra estudada quanto à problemática dos resíduos sólidos. Foi constatado que a amostra estudada mostrou ter uma razoável conscientização ambiental a respeito dos resíduos sólidos. Contudo, apesar de apresentar uma atitude positiva em relação aos resíduos, a maioria não demonstrou um comportamento condizente com essa atitude, esperando alguma ação do poder público.

PALAVRAS-CHAVE: Resíduos sólidos. Gestão e gerenciamento dos resíduos sólidos. Conscientização e educação ambiental.

\section{ABSTRACT}

This research aims to identify what actions are needed to increase the environmental awareness and the participation of the population in the proper environmentally management of solid waste. For this, it was needed to assess the problem of solid waste management by the perspective of the environmental awareness and of the engagement of the society. The study utilized an exploratory research with a quantitative focus. The data were collected through a questionnaire applied in municipalities present at the countryside of the state of São Paulo and at the Triângulo Mineiro, and they were analyzed by means of the descriptive statistics. The final result of this work was the development of a general picture that showed the perception of the sample studied as for the problem of solid waste. It was noted that the sample studied showed a reasonable environmental awareness about solid waste. However, although they presented a positive attitude in relation to waste, the majority did't show a behavior consistent with this attitude, expecting some action the part of the government.

KEYWORDS: Solid waste. Solid waste management. Environmental awareness and education.

\section{RESUMEN}

Esta investigación pretende identificar que acciones son necesarias para ampliar la concienciación ambiental y la participación de la población en la gestión ambientalmente adecuada de los residuos sólidos. Para ello, se evaluó la problemática de la gestión de los residuos sólidos bajo la óptica de la concienciación ambiental y del compromiso de la sociedad. El estudio realizado utilizó la investigación exploratoria con enfoque cuantitativo. Los datos fueron recolectados por medio de un cuestionario aplicado en municipios presentes en el interior del estado de São Paulo y en la región del Triángulo Minero, y fueron analizados por medio de la estadística descriptiva. El resultado final de este trabajo fue el desarrollo de un panorama general que mostró la percepción de la muestra estudiada en cuanto a la problemática de los residuos sólidos. Se constató que la muestra estudiada mostró tener una razonable concientización ambiental respecto a los residuos sólidos. Sin embargo, a pesar de presentar una actitud positiva hacia los residuos, la mayoría no demostró un comportamiento acorde con esa actitud, esperando alguna acción del poder público.

PALABRAS CLAVE: Residuos sólidos. Gestión y gestión de los residuos sólidos. Conscientización y educación ambiental. 


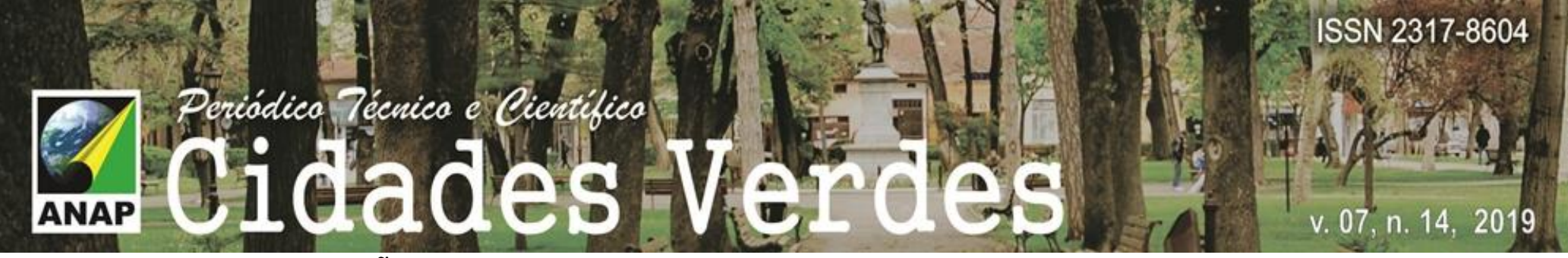

\section{INTRODUÇÃO}

Desde sua origem, o ser humano produz algum tipo de resíduo. Até a revolução industrial, o meio ambiente tinha capacidade de degradar esses resíduos. Contudo, a partir desse período, a quantidade e as características químicas, físicas e biológicas desses resíduos foram se alterando. Além disso, houve um aumento da população e do consumo, o que contribuiu para o crescimento da produção de resíduos sólidos, sendo que a capacidade de degradação da natureza permaneceu a mesma (ALBERTIN et al., 2010).

Segundo Schalch (2002), o manejo inadequado dos resíduos sólidos representa uma ameaça à saúde, contribui para a degradação ambiental, gera desperdícios e compromete a qualidade de vida das sociedades. A falta de tratamento ou a disposição final inadequada dos resíduos representam um problema aos aspectos sanitários, ambientais e sociais, como a degradação do solo, contaminação dos corpos d'água e mananciais, enchentes, poluição do ar, aparecimento de vetores e insalubridade (JACOBI e BESEN, 2011).

O desperdício representa outro desafio que o poder público precisa lidar. Em cidades de grande porte, o percentual de resíduos biodegradáveis vai de 50 a 60\%, já em cidades do interior do país a quantidade de matéria orgânica chega a atingir $80 \%$ segundo Mahler (2001). Além de caracterizar um elevado desperdício de nutrientes, ao serem descartados em terrenos baldios esses resíduos se tornam uma grande preocupação para o município relacionada ao saneamento (VIANA, 2005).

Esse desperdício é devido ao fato de que elevada parcela da população possui o hábito de descartar alimentos, tanto em restaurante como em suas residências (CALDERONI, 1999). Dessa forma, é necessário um sistema de gerenciamento e tratamento adequado dos resíduos sólidos, que incentive a separação nas fontes geradoras, amenize as consequências negativas para o meio ambiente e gere benefícios sociais e econômicos para a sociedade.

Cabe ao poder público promover soluções integradas para o problema dos resíduos sólidos. Para resolver a questão do desperdício, é necessário que se promovam campanhas e ações efetivas que considerem desde a educação nutricional e também outras formas de ação como a Educação Ambiental (Al), por considerar a importância da aquisição de novos comportamentos e atitudes, contribuindo para formação de novos cidadãos (ARANTES, 2017).

É necessário que as comunidades locais promovam a gestão dos resíduos sólidos urbanos (RSU), para reduzir a produção de resíduos, por meio da diminuição do consumo, da reutilização e da separação na fonte dos resíduos contaminantes (JACOBI e BESEN, 2011). Para tanto, questiona-se: Quais ações são necessárias para ampliar a consciência ambiental, de forma a promover a participação da população no processo de gerenciamento dos resíduos sólidos?

Nesse sentido, o objetivo desta pesquisa foi identificar ações necessárias para ampliar a conscientização ambiental e a participação da população na gestão ambientalmente adequada dos resíduos sólidos. 


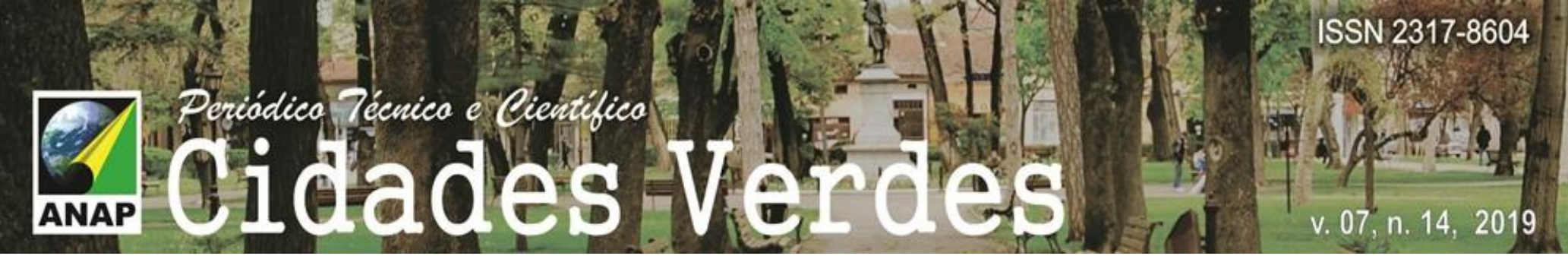

moderna. Assim, as ações no gerenciamento dos resíduos sólidos precisam ser agregadas entre si, devendo-se considerar a situação econômica e social da área em questão e sua urbanização, pois são fatores que intensificam essa problemática (FRÉSCA, 2007).

Segundo a Política Nacional de Resíduos Sólidos (PNRS) (BRASIL, 2010), a gestão dos resíduos sólidos está pautada em uma série de princípios, como a prevenção e precaução, visão sistêmica, desenvolvimento sustentável, ecoeficiência, cooperação entre os três setores da sociedade, o reconhecimento do resíduo como um bem econômico, dentre outros. 0 manejo dos resíduos sólidos é de responsabilidade da administração pública municipal, desde a coleta até a disposição final (JACOBI e BESEN, 2011), no entanto, a sociedade civil precisa fazer a sua parte para que o sistema alcance a sustentabilidade necessária.

\subsection{Gestão e gerenciamento integrado dos resíduos sólidos}

De acordo com a PNRS (BRASIL, 2010), no Capítulo II, art. 3, a gestão integrada dos resíduos sólidos (GIRS) pode ser definida como o "conjunto de ações voltadas para a busca de soluções para os resíduos sólidos, de forma a considerar as dimensões política, econômica, ambiental, cultural e social, com controle social e sob a premissa do desenvolvimento sustentável".

O gerenciamento integrado dos resíduos sólidos urbanos (GIRSU) pode também ser entendido como "o envolvimento de diferentes órgãos da administração pública e da sociedade civil com o propósito de realizar a limpeza urbana, a coleta, o tratamento e a disposição final do lixo" (IBAM, 2001, p. 8).

Segundo McDougall et al. (2001, p. 15), as características chave da sustentabilidade na gestão integrada de resíduos sólidos são: "(1)uma abordagem global; (2)uso de uma variedade de métodos de coleta e tratamento;(3)manejo de todos os materiais no fluxo dos resíduos; (4) ser ambientalmente eficaz; (5)economicamente acessível e (6)socialmente aceito" (trad. nossa).

De acordo com os autores Papargyropoulou et al. (2014), a hierarquia de prioridades na gestão de resíduos deve atender à seguinte ordem: redução, reutilização, reciclagem, tratamento e a disposição final adequada.

O poder municipal, para gerenciar os resíduos sólidos de forma integrada, tem que buscar prioridades como: a coleta dos resíduos; uma destinação final apropriada; a implementação de tratamentos de resíduos que atendam a requisitos ambientais e econômicos; a realização de campanhas educacionais e o incentivo a sua redução (SANTOS, 2002).

\subsection{Educação ambiental e conscientização}

Segundo Massukado (2004), um item fundamental a ser destacado no processo de GIRSU é a educação ambiental, que visa informar, alertar e conscientizar a população sobre as consequências da geração contínua de resíduos e permite uma mudança positiva no comportamento e nas atitudes da população em relação aos resíduos.

Jacobi e Bessen (2011) afirmam que são necessárias estratégias de redução de resíduos nas fontes geradoras, a serem alcançadas pela educação ambiental permanente. Os autores comentam sobre a importância de fazer a cobrança dos serviços relacionados aos RSU com 


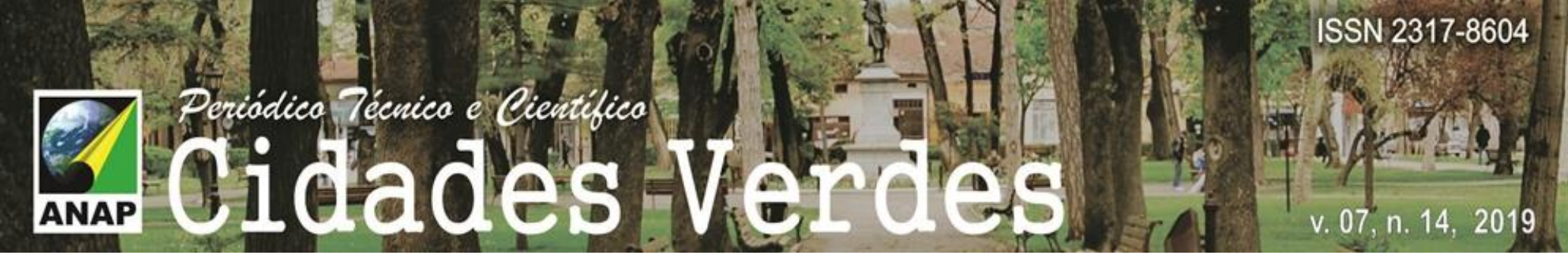

TABELA 1 - Cidades onde residem os respondentes.

\begin{tabular}{lcc}
\hline Cidade & Frequência & Percentual \\
\hline Barretos - SP & 26 & 23,2 \\
Bebedouro - SP & 2 & 1,8 \\
Conceição das Alagoas - MG & 1 & 0,9 \\
Colômbia - SP & 2 & 1,8 \\
Frutal - MG & 6 & 5,4 \\
Franca - SP & 1 & 0,9 \\
Jaborandi - SP & 1 & 0,9 \\
Jaboticabal - SP & 1 & 0,9 \\
Planura - MG & 44 & 39,3 \\
Ribeirão Preto - SP & 17 & 15,2 \\
São Carlos - SP & 1 & 0,9 \\
São José do Rio Preto - SP & 2 & 1,8 \\
Trabiju - SP & 1 & 0,9 \\
Uberaba - MG & 4 & 3,6 \\
Uberlândia - MG & 3 & 2,7 \\
\hline Total & $\mathbf{1 1 2}$ & $\mathbf{1 0 0}$ \\
\hline
\end{tabular}

Fonte: dos autores.

Após a coleta dos dados, estes foram analisados por meio da estatística descritiva. Esse tipo de análise corresponde a uma análise estatística simples que, segundo Silvestre (2007, p. 4), envolve um "conjunto de métodos destinados à organização e descrição dos dados através de indicadores sintéticos ou sumários".

\section{RESULTADOS E DISCUSSÕES}

A análise descritiva dos dados envolve questões relativas ao nível de conscientização e ao engajamento ambiental da população sobre a problemática dos resíduos sólidos e sua gestão. A primeira variável que foi analisada refere-se ao nível de valor agregado que a população dá aos resíduos sólidos. Neste quesito, mais da metade dos respondentes $(64,3 \%)$ acredita que os resíduos sólidos tenham muito valor agregado, sendo que somente $26,8 \%$ consideram que o lixo tenha pouco ou nenhum valor agregado.

Esse resultado segue uma direção oposta ao resultado que foi observado por Santos (2002) em sua pesquisa em Natal. Segundo o autor, $71,4 \%$ da amostra eram totalmente indiferentes ao valor que os resíduos sólidos poderiam oferecer. Essa diferença pode ser resultante da maior conscientização da população quanto aos resíduos sólidos, devido às diferenças regionais; ou pode ter ocorrido uma evolução ao longo dos anos sobre o conhecimento da população quanto à temática dos resíduos (MASSUKADO, 2004).

No que tange ao nível de preocupação sobre a questão dos resíduos, a maior parte dos respondentes (84\%) disse ter um nível alto e mediano de preocupação, enquanto que $16,1 \%$ apresentam um baixo nível ou nenhuma preocupação sobre esse tema. Esse resultado corrobora com a pesquisa de Santos (2002) em Natal, na qual a população dá importância às questões ambientais voltadas para projetos de gestão de resíduos sólidos. Segundo Farias e Fontes (2003), em uma entrevista com a Empresa de Serviços Urbanos de Aracaju (ENSURB), a maioria das pessoas da comunidade estudada, apesar do desconhecimento sobre a problemática dos resíduos, mostrou-se preocupada com essas questões ambientais. 
Sobre a questão da cidade possuir a prática de coleta seletiva, somente $25 \%$ dos respondentes não sabiam esse tipo de informação. $E$ dentre aqueles que responderam, quase metade $(46,4 \%)$ afirmou que esse tipo de atividade não havia em sua cidade. O problema é que muitas respostas não condiziam com as práticas realizadas pelos municípios, o que leva a crer que mais pessoas não sabiam responder a essa questão.

Em relação à prática de coleta seletiva pelos respondentes, mais da metade (58\%) afirmou que nunca realizou esse tipo de atividade, mas que estaria disposta a iniciar. Isso demonstra que a prática da coleta seletiva não é uma atividade comum entre os respondentes, no entanto, há muitas pessoas em potencial que estariam dispostas a iniciar tal prática.

Dentre aqueles que já praticam coleta seletiva (44 respondentes), 26,6\% afirmaram que um dos incentivos para iniciar tal atividade foi o fato de contribuir para a preservação da natureza. Em segundo lugar aparecem propagandas e campanhas com 18,1\% e em terceiro lugar escolas e universidades, e família e amigos, ambos com 17\%. Quanto à categoria outros, dois incentivos foram citados: "pós-graduação" e "programas em empresas nas quais trabalhei".

Dentre aqueles que nunca praticaram coleta seletiva (68 respondentes), o incentivo mais citado que poderia estimular tal atividade foi preservar a natureza $(24,6 \%)$. O segundo foi dispor de um centro de reciclagem próximo $(15,4 \%)$ e em terceiro as categorias "dispor de serviços e de uma infraestrutura voltada para coleta seletiva"; e "escolas e universidades", ambos com 12,3\%. Santos (2002), em sua pesquisa, também investigou qual seria a motivação para participar de um programa de coleta seletiva. Dois resultados foram mais significativos: $46,3 \%$ da amostra participariam para obter a melhoria do meio ambiente e $27,3 \%$ participaria para obter uma vantagem financeira.

Considerando novamente todos os respondentes, em relação aos resíduos sólidos especiais que os respondentes podem separar, 33,7\% afirmaram que separam pilhas e baterias, $15,4 \%$ separam lâmpadas fluorescentes e 13,9\% separam medicamentos. Quanto à categoria outros, oito resíduos sólidos foram citados, incluindo resíduos comuns e resíduos especiais, como "eletrônicos usados e móveis" e "equipamentos de informática e celulares".

Para aqueles que não separam nenhum resíduo sólido especial, uma pergunta aberta foi feita questionando se esses respondentes sabiam, ao menos, qual seria a destinação correta para esses resíduos. Ao todo, 43,3\% dos respondentes disseram não saber tal informação e $10 \%$ deixaram a pergunta em branco. Assim, pode-se concluir que praticamente metade dos respondentes $(53,3 \%)$ não tinha conhecimento sobre a forma de destinação adequada para os resíduos especiais.

Além disso, dentre aqueles que responderam à questão (46,7\%), havia muitas respostas vagas ("eu sei que existem locais em que se depositam os resíduos sólidos especiais"), ou respostas para apenas um ou outro resíduo específico ("existem empresas que coletam pilhas e baterias, mas o destino que elas dão para esses resíduos após a coleta, eu desconheço; já sobre os outros citados, não tenho ideia aonde devo descartar").

Para aqueles que já separam algum tipo de resíduo sólido especial, 35,3\% demonstraram que não sabiam informar qual seria a destinação correta para esses resíduos. Dentre aqueles que responderam $(64,6 \%)$, muitos citaram organizações privadas e públicas como forma de destinação apropriada dos resíduos sólidos especiais. A maioria das respostas era especificada 
para alguns resíduos, ou seja, a maioria dos respondentes não tinha conhecimento sobre a forma de destinação adequada para todos os resíduos especiais citados.

Alguns respondentes afirmaram que guardavam em casa os resíduos especiais que separavam, outros deram respostas vagas ("para locais destinados a este tipo de lixo"; "não há um lugar específico, apenas separa o lixo de maneira a facilitar seu destino"). Além disso, houve várias respostas inadequadas, como "geralmente procuro queimar os resíduos que são possíveis"; "para o lixão ou para um centro de reciclagem [...]"; "em lugares afastados de construções, e que não tenha contato com animais silvestres, e não prejudique o ser humano de alguma maneira" (sobre pneus).

As respostas consideradas corretas, que se esperava obter, eram realizar a reutilização desses materiais de forma adequada ou sua destinação apropriada. A solução ideal para os resíduos de construção civil é a reciclagem e sua reutilização, mas sua destinação em aterros sanitários representa uma solução viável, quando o material de cobertura dos resíduos é escasso. Quanto aos pneus, deve-se reciclá-los, sendo que sua forma correta de destinação seria triturá-los e descartá-los em aterros sanitários (IBAM, 2001).

As pilhas e baterias devem ser entregues aos revendedores ou às redes de assistência técnica autorizada (ZANARDI JR., 2012), e devem ser tratadas como resíduos perigosos Classe I (IBAM, 2001). Já as lâmpadas fluorescentes devem ser recicladas ou gerenciadas como resíduos tóxicos. Tanto as pilhas e baterias quanto as lâmpadas fluorescentes são resíduos perigosos, por isso devem ser destinadas aos aterros Classe I (IBAM, 2001).

Já os medicamentos fazem parte dos resíduos dos serviços de saúde, por isso, eles devem ser destinados a hospitais, postos de saúde, clínicas veterinárias, entre outros, sendo que eles são considerados resíduos especiais classe B (IBAM, 2001). Segundo a resolução no 358 do CONAMA (29/04/2005), os resíduos pertencentes ao grupo B com característica de periculosidade, caso não forem submetidos a um processo de reutilização, recuperação ou reciclagem, devem ser tratados e dispostos em locais específicos (CONAMA, 2006).

Em relação à opinião dos respondentes quanto ao melhor método de disposição dos resíduos sólidos, $12,5 \%$ afirmaram que não sabiam qual seria a destinação adequada. Quase metade dos respondentes $(44,6 \%)$ acredita que a melhor destinação para os resíduos sólidos seria tanto os aterros controlados quanto os aterros sanitários. Isso demonstra que, em geral, as pessoas não têm conhecimento da diferença entre as duas formas de aterro.

Os vazadouros a céu aberto ou lixões são uma forma inapropriada de destinação final dos resíduos sólidos, pois não recebem tratamento e podem contaminar o solo com metais pesados, como indicam Cavallet, Carvalho e Fortes Neto (2013). Os lixões trazem diversos problemas ambientais, sociais e econômicos, pois além de contaminarem o solo e as águas subterrâneas, dão oportunidade a catadores clandestinos, além da emissão de gases de efeito estufa (TONETO JR. et al., 2008). Já nos aterros controlados, os resíduos presentes no solo são recobertos por terra, embora tenham uma eficácia bem inferior aos aterros sanitários (CUNHA e CAIXETA FILHO, 2002).

Quanto à questão sobre o local onde o poder municipal destina os resíduos sólidos, $36,6 \%$ afirmaram não saber para onde esses resíduos eram enviados, e 36,6\% da amostra afirmaram que o município destinava os resíduos a vazadouros a céu aberto. Um resultado similar foi 
observado pela pesquisa do IBGE (2008), que mostrou que a maioria dos municípios enviava seus resíduos para vazadouros a céu aberto (50,8\%), enquanto $22,5 \%$ destinam em aterros controlados, e somente $22,7 \%$ destinam em aterros sanitários. Esses números vêm sendo melhorados, principalmente a partir da implantação dos planos de saneamento básico nos municípios brasileiros.

No que tange à frequência com que os respondentes evitam o desperdício, quase metade da amostra $(49,1 \%)$ raramente tem esse tipo de atitude, enquanto que $43,7 \%$ sempre possui esse comportamento. Santos (2002), em sua pesquisa, avaliou o comportamento de reduzir ou reciclar os resíduos que se produz. Ele obteve um resultado similar: $48,78 \%$ dos respondentes afirmaram que nunca tentaram reduzir os resíduos que produziam em suas casas, enquanto que $10,2 \%$ relataram que sempre apresentavam esse comportamento.

Mais da metade da amostra $(54,5 \%)$ raramente leva em consideração o fato de um produto ter sido produzido com materiais recicláveis. Ao todo, $75,9 \%$ nunca ou raramente levam esse fator em consideração, e somente $24,1 \%$ frequentemente ou sempre consideram essa característica. Um resultado similar foi observado por Velter et al. (2009), ao concluírem que há pouca diferença na média das atitudes ao considerar a embalagem e a marca com argumentos ecológicos (VELTER et al., 2009).

Mais da metade dos respondentes $(58,9 \%)$ não aceitaria dividir o custo de gerenciar os resíduos sólidos com o município e somente $45,3 \%$ aceitariam pagar uma parte do custo ou todo o custo. A cobrança pelo serviço de gestão dos resíduos sólidos é mais significativa na região Sul e Sudeste, quando comparada com outras regiões (IBGE, 2008). Essa cobrança é muito importante, pois segundo Leite (2006), ela tem o objetivo de cobrir os custos advindos da gestão do processo, que envolve os serviços de coleta, transporte e destinação.

Como observaram Estival et al. (2008), a gestão dos resíduos sólidos é um desafio para os municípios, que têm enfrentado diversas dificuldades: o aumento na geração de resíduos, a falta de locais apropriados para a destinação e tratamento e o alto custo de praticar a coleta seletiva. Com a PNRS (BRASIL, 2010) espera-se alcançar melhorias nesses aspectos.

Dos respondentes, 30,3\% sugeriram, como forma de elevar a conscientização ambiental sobre os resíduos sólidos, o incremento da educação ambiental em escolas e universidades. Já $29 \%$ recomendaram aumentar o índice de propagandas e campanhas voltadas para esse fim e 27,2\% indicaram tornar a legislação mais rigorosa. Santos (2002) obteve um resultado um pouco diferente em sua pesquisa sobre as formas eficazes de conscientizar a população. Em seu estudo, $44,1 \%$ dos respondentes afirmaram que as multas seriam a melhor forma de conscientizar os cidadãos.

A consciência ambiental foi estimulada com o aumento das denúncias sobre os problemas ambientais, o que elevou o número de normas, regulamentos e órgãos responsáveis por fiscalizar a aplicação desses instrumentos legais. $O$ quadro 1 sintetiza os principais aspectos encontrados na pesquisa. 


\begin{tabular}{|c|c|}
\hline Aspectos & Resultados encontrados \\
\hline Valor agregado dos RSU & $\begin{array}{l}64,3 \% \text { acreditam que os resíduos sólidos tenham muito valor } \\
\text { agregado }\end{array}$ \\
\hline Nível de preocupação com os RSU & $84 \%$ disseram ter um nível alto e mediano de preocupação \\
\hline \multirow{3}{*}{ Coleta seletiva no município } & $25 \%$ não sabiam esse tipo de informação \\
\hline & Dos que responderam, $46,4 \%$ afirmaram não haver em sua cidade \\
\hline & Muitas respostas não condiziam com o que havia no município \\
\hline Seleção dos resíduos & $\begin{array}{l}58 \% \text { afirmaram que nunca realizaram, mas que estariam dispostos a } \\
\text { iniciar }\end{array}$ \\
\hline Incentivo para a coleta seletiva & Contribuir para a preservação da natureza \\
\hline $\begin{array}{l}\text { Principais resíduos especiais separados pelos } \\
\text { respondentes }\end{array}$ & Pilhas, baterias, lâmpadas fluorescentes e medicamentos \\
\hline $\begin{array}{l}\text { Conhecimento sobre a destinação adequada } \\
\text { desses resíduos especiais }\end{array}$ & $53,3 \%$ dos respondentes não tinham conhecimento \\
\hline \multirow{3}{*}{ Destinação dos RSU } & $12,5 \%$ afirmaram não saber \\
\hline & $\begin{array}{l}44,6 \% \text { acreditam que a melhor destinação seria tanto os aterros } \\
\text { controlados quanto os aterros sanitários }\end{array}$ \\
\hline & $\begin{array}{l}\text { Falta de conhecimento da diferença entre as duas formas de } \\
\text { destinação }\end{array}$ \\
\hline \multirow{2}{*}{$\begin{array}{l}\text { Local onde o poder municipal destina os } \\
\text { resíduos sólidos }\end{array}$} & $36,6 \%$ afirmaram não saber \\
\hline & $36,6 \%$ disseram ser para vazadouros a céu aberto \\
\hline \multirow{2}{*}{ Atitude de evitar o desperdício } & $49,1 \%$ raramente têm esse tipo de atitude \\
\hline & $43,7 \%$ sempre possuem esse comportamento \\
\hline Produtos feitos com materiais recicláveis & $75,9 \%$ nunca ou raramente levam esse fator em consideração \\
\hline \multirow{2}{*}{ Custo de gerenciar os resíduos sólidos } & $58,9 \%$ não aceitariam dividir o custo com o município \\
\hline & $45,3 \%$ aceitariam pagar uma parte do custo ou todo o custo \\
\hline \multirow{3}{*}{ Ações recomendadas } & $\begin{array}{l}\text { 30,3\% sugeriram o incremento da educação ambiental em escolas e } \\
\text { universidades }\end{array}$ \\
\hline & $\begin{array}{l}29 \% \text { recomendaram aumentar o índice de propagandas e } \\
\text { campanhas }\end{array}$ \\
\hline & $27,2 \%$ indicaram tornar a legislação mais rigorosa \\
\hline
\end{tabular}

QUADRO 1 - Síntese dos resultados encontrados. Fonte: dos autores.

A construção do conhecimento sobre o meio ambiente pode ser alcançada com a educação ambiental, para que o ser humano possa ser crítico e quebrar seus paradigmas (SANTOS et al., 2013), de forma a se obter uma consciência coletiva que leve ao desenvolvimento sustentável.

\section{CONCLUSÕES}

O presente trabalho buscou informações sobre características da gestão e gerenciamento de resíduos sólidos de um conjunto de respondentes da região do Triângulo Mineiro e do interior do estado de São Paulo. Levou-se em consideração a conscientização e o envolvimento ambiental da amostra com o tema, de forma a identificar ações para conscientizar e ampliar a 
participação da população no processo de gestão dos resíduos sólidos, e consequentemente, promover sua mudança de hábitos.

Ao se comparar essa pesquisa com a pesquisa de Santos (2002), nota-se que houve uma evolução positiva na conscientização da população quanto à temática dos resíduos sólidos. Este fato é possivelmente justificado pela maior exposição da situação dos resíduos no Brasil nos meios de comunicação e no setor educacional. No entanto, o nível de comportamento proativo permaneceu o mesmo. Ou seja, por mais que a sociedade soubesse desses problemas, ela não tomou iniciativas para amenizá-los.

A pesquisa mostrou que os respondentes têm uma razoável conscientização ambiental a respeito dos resíduos sólidos. Contudo, apesar de apresentar uma atitude positiva em relação aos resíduos, a maioria não demonstrou um comportamento condizente com essa atitude, esperando alguma ação somente por parte do poder público. Possivelmente essas atitudes são reflexos de um desejo de se sentirem ecologicamente corretos, mas que não se eleva a ponto de transformarem-se em comportamentos proativos.

Nesse sentido, ações voltadas para a educação ambiental, campanhas e propagandas para elevação do conhecimento para a conscientização da população sobre os aspectos dos resíduos e seus impactos no meio ambiente, maior divulgação do que os municípios estão fazendo com seus resíduos, além de incentivos não necessariamente coercitivos, seriam importantes para a maior participação da população na gestão ambientalmente adequada dos resíduos sólidos.

\section{REFERÊNCIAS}

ADISSI, P. J.; PINHEIRO, F. A.; ROSÂNGELA, S. C. (Org.). Gestão Ambiental de Unidades Produtivas. Rio de Janeiro: Elsevier, 2013.

ALBERTIN, R. M et al. Diagnóstico da gestão dos resíduos sólidos urbanos do município de Flórida Paraná. Revista Agro@mbiente On-line, v. 4, n. 2, p. 118-125, jul.-dez. 2010.

ARANTES, C. A. Desperdício de alimentos e geração de resíduos sólidos biodegradáveis no restaurante universitário do campus Santa Mônica da Universidade Federal de Uberlândia/MG. Períodico técnico e científico Cidades Verdes, v. 5, n. 11, 2017.

ASSOCIAÇÃO BRASILEIRA DE NORMAS TÉCNICAS (ABNT). Norma NBR 10.004: Resíduos Sólidos - Classificação. Rio de Janeiro: ABNT, 2004.

AZAMBUJA, E. A. K. Proposta de gestão de resíduos sólidos urbanos - análise do caso de Palhoça/SC. Dissertação (Mestrado em Engenharia de Produção)-Universidade Federal de Santa Catarina, Florianópolis, 2002.

BRASIL. Presidência da República. Lei № 12.305, de 2 de agosto de 2010. Institui a Política Nacional de Resíduos Sólidos; altera a Lei no 9.605, de 12 de fevereiro de 1998; e dá outras providências. Disponível em: <https://www.planalto.gov.br/ccivil_03/_ato2007-2010/2010/lei/I12305.htm>. Acesso em: 10 jul. 2014.

CALDERONI, S. Os Bilhões Perdidos no Lixo. 3. ed. São Paulo: Humanitas, 1999. 343 p.

CAVALLET, L. E.; CARVALHO, S. G.; FORTES NETO, P. Metais pesados no rejeito e na água em área de descarte de resíduos sólidos urbanos. Revista Ambiente \& Água [online], v. 8, n. 3, p. 229-238, 2013.

CONSELHO NACIONAL DO MEIO AMBIENTE (CONAMA). Resoluções vigentes publicadas entre julho de 1984 e maio de 2006. Ministério do Meio Ambiente - MMA. Brasília, 2006. Disponível em: 


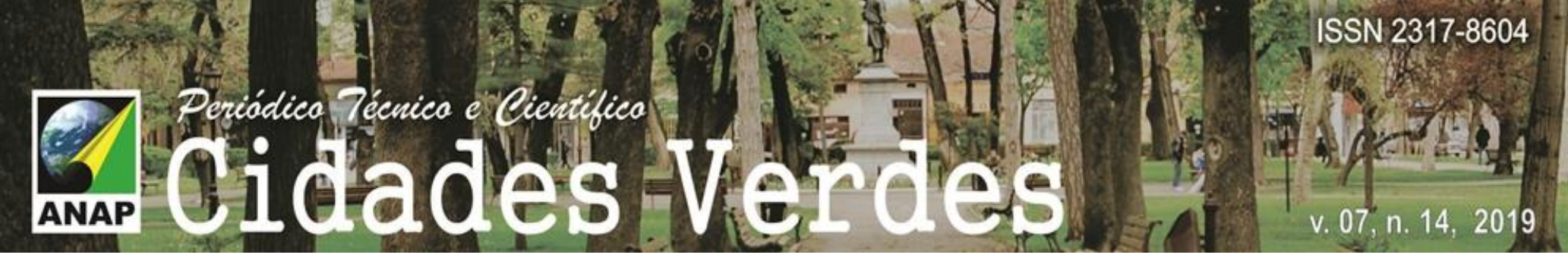

<http://www.iap.pr.gov.br/arquivos/File/Legislacao_ambiental/Legislacao_federal/Resolucoes_CONAMA/COLETAN EA_DE_\%20RESOLUCOES_DO_\%20CONAMA_DE_2008.pdf>. Vários acessos, 2014.

CUNHA, V.; CAIXETA FILHO, J. V. Gerenciamento da coleta de resíduos sólidos urbanos: estruturação e aplicação de modelo não-linear de programação por metas. Gestão e Produção, v. 9, n. 2, p. 143-161, ago. 2002.

DEMAJOROVIC, J. Da política tradicional de tratamento do lixo à política de gestão de resíduos sólidos. As novas prioridades. Revista de Administração de Empresas, São Paulo, v. 35, n. 3, p. 88-93, maio-jun. 1995.

ESTIVAL, K. G. S. et al. Análise das percepções e ações dos consumidores na cadeia reversa de pós-consumo dos resíduos sólidos urbanos no município de Ilhéus/BA. In: ENCONTRO NACIONAL DE ENGENHARIA DE PRODUÇÃO, 27., Rio de Janeiro, 13 a 16 de outubro de 2008. Anais do XXVII ENEGEP. Rio de Janeiro: ABEPRO, 2008.

FARIAS, J. S.; FONTES, L. A. M. Gestão integrada de resíduos sólidos: o lixo de Aracaju analisado sob a ótica da gestão de meio ambiente. Centro de Pesquisas em Administração, São Paulo, v. 10, n. 2, p. 95-105, abr.-jun. 2003.

FRÉSCA, F. R. C. Estudo da geração de resíduos sólidos domiciliares no município de São Carlos/SP, a partir da caracterização física. Tese (Mestrado em Ciências da Engenharia Ambiental)-Escola de Engenharia de São Carlos,Universidade de São Paulo, São Carlos, 2007.

INSTITUTO BRASILEIRO DE ADMINISTRAÇÃO MUNICIPAL (IBAM). Manual Gerenciamento Integrado de Resíduos Sólidos. 2001. Disponível em: <http://www.resol.com.br/cartilha4/manual.pdf>. Acesso em: 2 maio 2012.

INSTITUTO BRASILEIRO DE GEOGRAFIA E ESTATÍSTICA (IBGE). Pesquisa Nacional de Saneamento Básico, 2008. Disponível em: <http://www.ibge.gov.br/home/estatistica/populacao/condicaodevida/pnsb2008/PNSB_2008.pdf>. Acesso em: 27 abr. 2012.

JACOBI, P. R.; BESEN, G. R. Gestão de resíduos sólidos em São Paulo: desafios da sustentabilidade. Estudos Avançados [online], v. 25, n. 71, p. 135-158, 2011.

LEITE, M. F. A taxa de coleta de resíduos sólidos domiciliares: uma análise crítica. Dissertação (Mestrado em Engenharia Civil)-Escola de Engenharia de São Carlos, Universidade de São Paulo, São Carlos, 2006.

MAHLER, C. Lixo: o que fazer com ele? Revista do CREA, Rio de Janeiro, n.33, p. 10 - 13, jan/fev, 2001.

MASSUKADO, L. M. Sistema de apoio à decisão: avaliação de cenários de gestão integrada de resíduos sólidos urbanos domiciliares. Dissertação (Mestrado em Engenharia Urbana)-Universidade Federal de São Carlos, São Carlos, 2004.

MCDOUGALL, F.; WHITE, P.; FRANKE, M.; HINDLE, P. Integrated solid waste management: a life cycle inventory. 2nd. ed. Oxford, UK: Blackwell Science, 2001.

PAPARGYROPOULOU, E. et al. The food waste hierarchy as a framework for the management of food surplus and food waste. Journal of Cleaner Production, v. 76, n. 1, p. 106-115, Aug. 2014.

SAMPIERI, F. H.; COLLADO, F. C.; LUCIO, P. B. Metodologia de Pesquisa. 3. ed. São Paulo: McGraw-Hill, 2006.

SANTOS, E. M. S. Gestão dos resíduos sólidos: um estudo da conscientização ambiental em uma cidade do Brasil. Dissertação (Mestrado em Ciências em Engenharia de Produção)-Universidade Federal do Rio Grande do Norte, Natal, 2002.

SANTOS, R. M. S. et al. A necessidade de uma nova conscientização ambiental: A educação ambiental como prática. REBES Revista Brasileira de Educação e Saúde (Pombal - PB, Brasil), v. 3, n. 2, p. 28-33 abr.-jun. 2013.

SCHALCH, V. et al. Gestão e gerenciamento de resíduos sólidos. São Carlos: Universidade de São Paulo, 2002.

SILVESTRE, A. L. Análise de dados e estatística descritiva. Lisboa: Escolar Editora, 2007.

TONETO JÚNIOR, R.; SAIANI, C. C. S.; DOURADO, J. Resíduos Sólidos no Brasil - Oportunidades e Desafios da Lei Federal n¹2.305 (Lei de Resíduos Sólidos). Barueri: Manole, 2013. p. 295-320. 


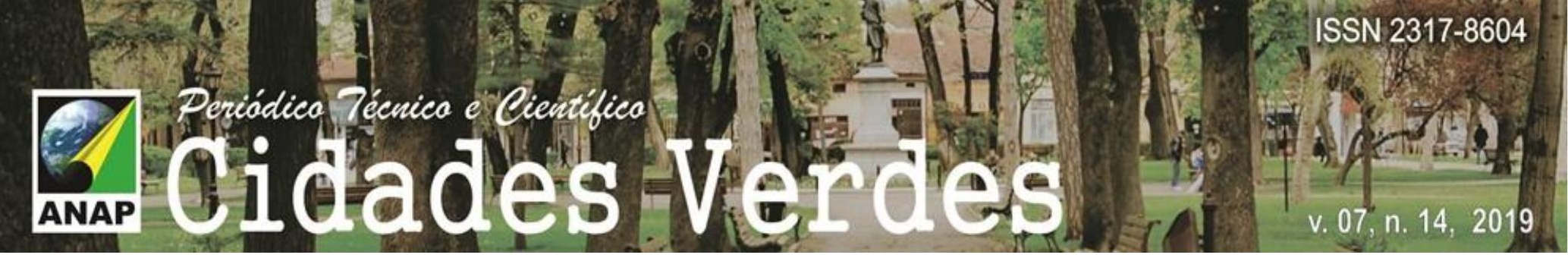

VELTER. A. N. et al. Atitude dos consumidores a partir da teoria das pistas e da consciência ambiental: contribuições ao estudo do green marketing. Revista de Administração da UFSM, Santa Maria, v. 2, n. 3, p. 399-416, set.-dez. 2009.

VIANA, E.; SCHULZ, H. E.; R. ALBUQUERQUE; NORONHA A. B. Resíduos sólidos alimentares do lixo domiciliar: Estudo do uso na alimentação de frangos de corte. Revista brasileira de Engenharia Agrícola e Ambiental, v. 10, n. 1, p. $203-211,2005$.

ZANARDI JR., V. Instrução Normativa no. 8 de 3 de setembro de 2012. Diário Oficial da União - Seção 1, n. 172, 2012. 